\title{
New process development from the theory of creative invention: application in logistics management of airport cargo
}

\author{
Jéssica Traguetto, Mauro Caetano, Cândido Borges, Vicente da Rocha Soares Ferreira \\ Universidade Federal de Goiás \\ e-mails: jessicatraguetto@gmail.com; maurocaetano1912@gmail.com; candido@face.ufg.br; vicenterochas@uol.com.br
}

\begin{abstract}
Within the scope of logistics, studies about air transportation have brought high relevance since this is a mode of transport with significant growth rate in recent years and considerable economic and social contribution. In this context, the air cargo terminals are strategic components for logistics, however, present a few data, especially when it comes to the analysis of ground services. This study uses the TRIZ methodology to identify the limitations and possibilities of innovation in logistics operations of an airport terminal cargo. The results demonstrate that the adoption of strategies could significantly improve storage of loads in storage disposition and thus the operational quality. Other results are presented in order to reconcile theory and practice on the gaps identified. As a suggestion for future research, is proposed to implement the proposals in a larger amount of actual cases in order to be evaluated results and quantitative implications.
\end{abstract}

Keywords: innovation, cargo terminal, new process development, TRIZ.

\section{Introduction}

Recent field of study, but in little more than fifty years already stands out on the international stage, the logistics are directly related to the strategic decisions of several types of organizations. According to a study by the United Nations Conference on Trade and Development - UNCTAD (2003), logistics costs, specifically the cost of international freight, have an impact on world trade as significant as tariff barriers.

The Airports Council International - ACI (2004) supports the assertion that, due to the globalization of production and the need for increased productivity, business success is linked to good logistics management. Bowersox and Closs (1997) argue that assumption stating that gain and maintain competitive advantage, for the most aggressive companies, are intrinsic to logistics. This implies that logistics is related to the reconfiguration of the operating systems aiming to adapt to customer needs and thus makes it more relevant for the same. Allied to this, the emergence of production systems just-in-time, for example, demand the increased speed of delivery of goods by the companies. To meet this market demand, one of the possibilities available to the logistics of production systems refers to the use of air transportation by companies to distribute their products.

However, the cost of air travel is presented as a factor limiting their demand, usually modal prices that are five times higher than the road and comes up to sixteen times the price of shipping (WORLD..., 2009). Still, due to benefits generated by fast delivery, this form of transport has been increasingly used.
As envisaged in the Boeing (2011), by 2029 the air transport present a growth of almost twice the rate of global GDP growth. Furthermore, we predict that the percentage of freighters go from the current $27 \%$ to $33 \%$ of the air fleet in 2029. The global supply chain, including manufacturing processes, assembly and distribution of goods are responsible for much of the increase in air traffic. The increase in capacity available, the best performances, best deals on aviation fuels, environmental regulations and national incentives for the business are also factors that affect growth rates in the industry (BOEING, 2011).

The speedy delivery is one of the main advantages of using air freight as it enables the reduction of inventory costs, the diversification of the local manufacturing of products and reduces the time to deliver the goods to the customer. However, the delay incurred at customs that affect agility, especially in imports in the customs clearance process has become slower, increasing the storage period of cargo in bonded warehouses by the Internal Revenue Service of Brazil. Thus, it becomes necessary to thorough analysis of the components and properties of the process of import cargo terminals installed in airports, which operate on intermodality, in order to improve their competitiveness (HSU; SHIH; WANG, 2009).

In this sense, the search for improvements in the use of this mode, one of the challenges is to identify managerial shortcomings and propose new solutions. One way better to understand this issue presents itself through TRIZ 
(Theory of Inventive Problem Solving) methodology solving problems facing the process innovative and creative in problem solving.

Currently still notices the little existence of studies for the practical test of this methodology, because most studies only explore the benefits associated with knowledge from the TRIZ (LLEVBARE; PROBERT; PHAAL, 2013). Accordingly, the present study aims to examine the feasibility of applying TRIZ to develop new logistics processes. For this, the focus of the study is on studying the particulars of an airport terminal and cargo using TRIZ, according to the model proposed by Chai, Zhang and Tan (2005), to identify potential innovations for the development of improvements in logistics management. Because it is a strategic business unit, your name and location not be disclosed at work, however, it is a terminal Brazilian cargo airport.

It shows a lack of research with a focus on the ground services of air cargo terminals (HAN; CHOU; LIANG, 2003). For Ohashi et al. (2005), the cause of this gap can be among others, the lack of information about the internal logistics activities operating in the cargo terminals. This study can be used as a reference to support innovation in the management of air transport, especially in ground operations.

\section{Background: logistics and the Theory of Inventive Problem Solving (TRIZ)}

The Council of Supply Chain Management Professionals - CSCMP (2013) defines Supply Chain
Management as an integrating function, which includes all logistics management activities, but with the responsibility to link the main functions and processes inter and intrafirm a business model high performance.

The Council of Supply Chain Management Professionals - CSCMP (2013) considers that the planning, execution and control of all operations ranging from the point of origin to point of consumption are the responsibility of Logistics Management. Notably, the scope of this concept, in which the scope of logistics all levels of planning and executing strategic, operational and tactical are included. From this concept, it can be stated that logistics is presented as an integrating function which coordinates different activities, and integrate them with other functions such as marketing, sales, production, finance and information technology.

According to the United Nations Conference on Trade and Development - UNCTAD (2003), logistics services include management activities, and in many cases also providing packing services, storage, and transportation information within a supply chain.

Ballou (1997) argues that the management of these activities represents a significant contribution to the logistic service of the customer. Figure 1 represents the typical logistic activities.

According to Figure 1, the activities of the supply chain are classified into two different groups. The first group (1) involves the flow of inputs and outputs from the point of acquisition to the supplier operations, thus termed as "physical supply". The second group of activities (2) starts from operations to customer thus receives the name of

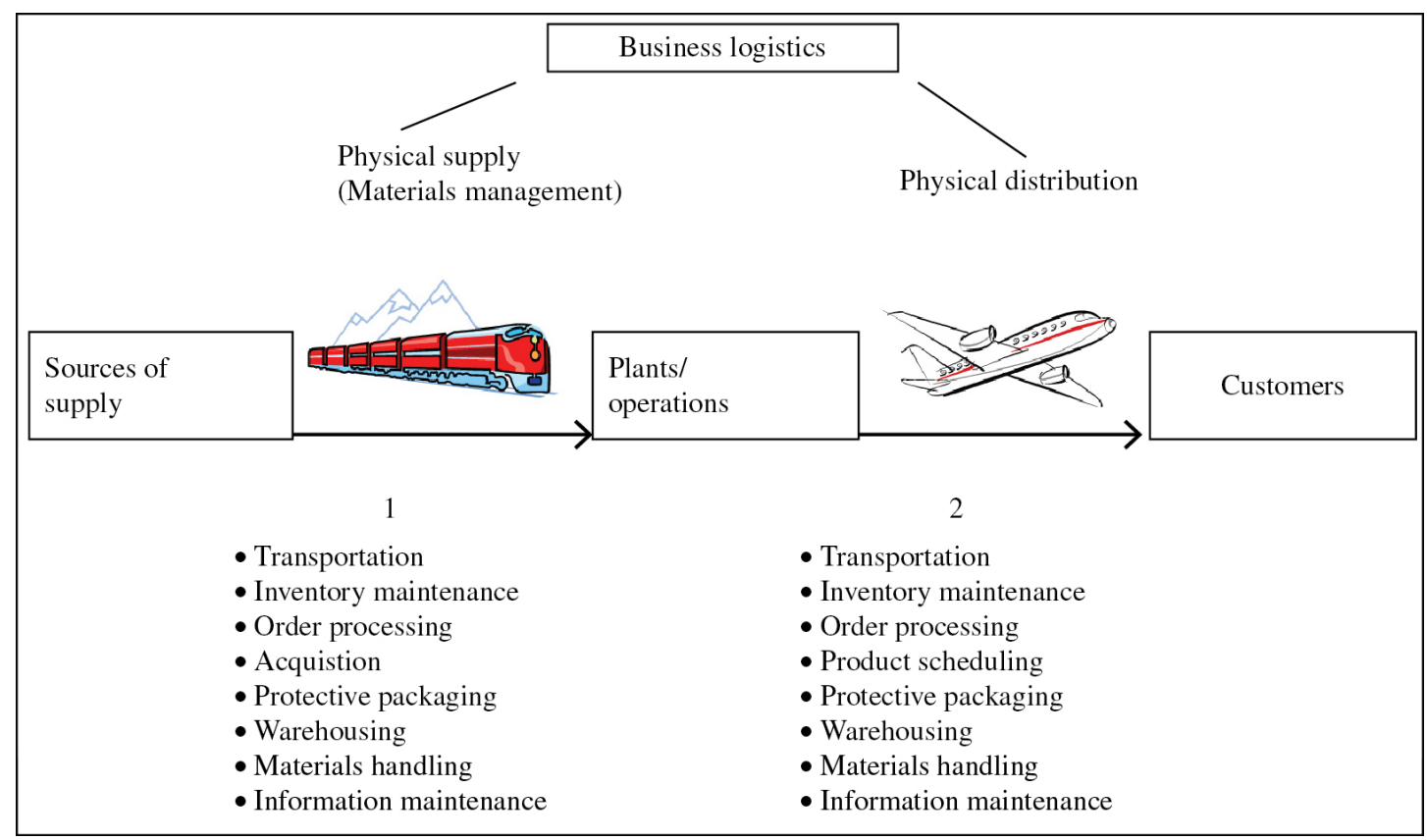

Figure 1. Typical activities in a firm's immediate supply chain. Source: Ballou (1997) - adapted by the authors. 
"physical distribution". Although these two groups of activities they are substantially the same, there is a difference between the types of product before operations because it is believed that the materials are in the process of receiving the value promoted by aggregation operations, before operations are raw materials and products are after with the value of organizations, which can result in different costs of transportation, inventory maintenance, etc.

Several processing steps that combine into a complex network of information and material flow, so Van Oudheusden and Boey (1994) characterize the operation of an air cargo terminal. These stages are usually the following: customs control, documentation, consolidation and deconsolidation of aircraft pallets, called ULD (unit load device), transportation and other material handling operations. The efficiency of the storage system is shown to be significant in the aspect of optimizing the operational flow of the terminal.

Given all the challenges of competition in a global context, the cargo terminal of an international airport has the need to improve their terrestrial services, such as wharfage, warehousing, customs support and supervision, and support systems to the flow information (HAN; CHOU; LIANG, 2003).

Yat-Wah Wan et al. (1998) classifies the supply chain of air cargo into four major groups: airlines; customers (senders and receivers); cargo terminals of airports and cargo agents. There are some processes that resemble both imports and in exports. In both, the following interactions occur: air transportation is provided by the airlines; the interface between air and the ground is due to the cargo terminal, and finally hiring transportation and documentation to customers are carried by cargo agents, as shown in Figure 2.

Yat-Wah Wan et al. (1998) also highlight the importance of cargo agents in the chain because according to the authors, they play the role of intermediaries to the flow of information between airlines, cargo terminal and customers. In some cases even coordinate the physical movement of goods.

Innovations for a business are recognized as of high value to a company, from a small shop to a large multinational.
From this context, the TRIZ - Russian acronym for "Theory of Inventive Problem Solving" - consists in a methodology for problem solving focused on efficiency, effectiveness and creativity (SAVRANSKY, 2000). The initial application refers to 1946, when G. Altshuller, a mechanical engineer, began studying the patents of the Russian Navy to identify the source of creative solutions (LI, 2010). Among the many kinds of concepts, heuristics and universal instruments troubleshooting, note that there are those appropriate for particular types of non-technical issues, and there are also some that are applied in only a few areas of engineering. TRIZ handles both types of concepts, with an emphasis on literature for universal instruments (SAVRANSKY, 2000).

The application of TRIZ was held at a Brazilian airport cargo terminal following the model proposed by Chai, Zhang and Tan (2005), which includes three main phases, according to the scheme of Figure 3.

With this emphasis on the universal principles of the invention, the TRIZ methodology seeks deepening and energizing the creative process, on the assumption that identifying and codifying the principles creative, they can be taught. For this, in the last fifty years there has been analyzing more than two million patents seeking to identify regularities and creative principles. Resulting from this search, three conclusions were made: 1) In industry and science problems and solutions are repeated;2) patterns of technical evolution also repeated in these areas; 3) Innovations for a product or service being developed using scientific purposes outside the field of activity (LÓPEZ; ALMEIDA; ARAUJO-MOREIRA, 2005).

There is a significant effort to expand the potential applications of TRIZ in different areas. The several tools can be equally effective in solving technical problems and non-technical. Accordingly, Mann and Domb (1999) adapted to business management the 40 inventive principles proposed by TRIZ, considered as the tool more accessible and useful methodology. Another work worth mentioning is that of Zhang, Chai and Tan (2003), who interpreted the 40 inventive principles with examples in operations management and services.

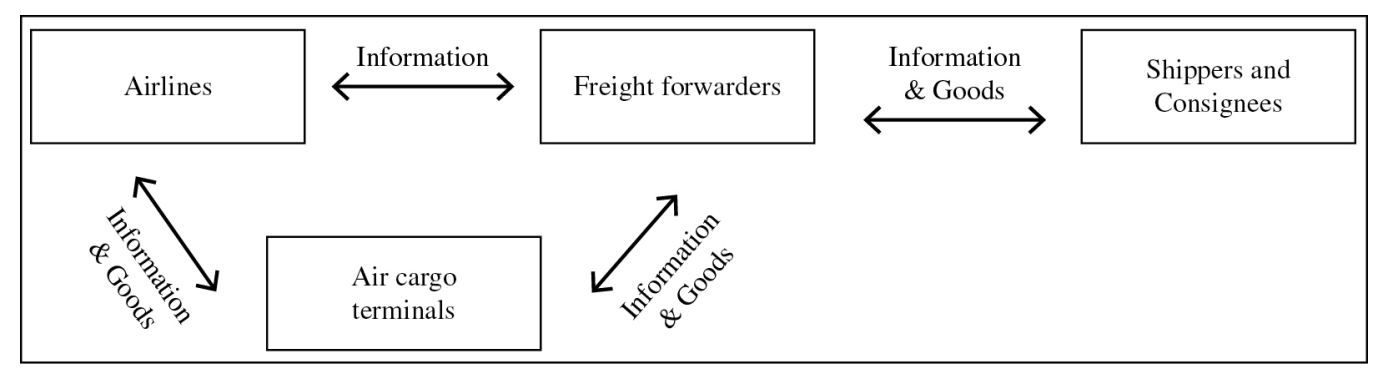

Figure 2. The relationships among different parties in the air-cargo industry. Source: Yat-Wah Wan et al. (1998). 


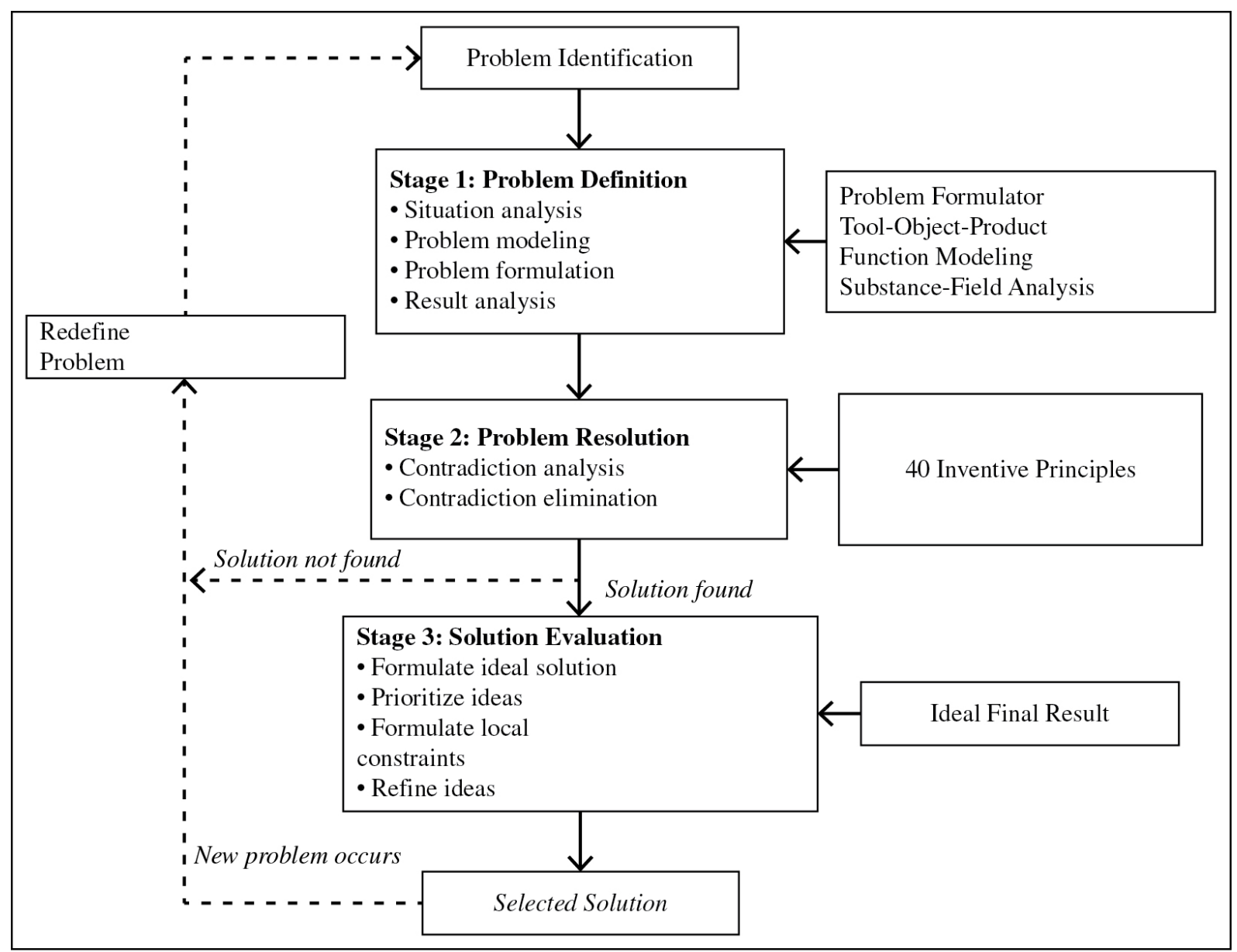

Figure 3. Scheme for the application of TRIZ. Source: adapted from Chai, Zhang and Tan (2005).

Essentially, the forty inventive principles of TRIZ are a set of suggestions that help in problem solving. These principles were prepared for more than a quarter century, but as demonstrated in the study of Belski et al. (2003), remain valid in the current context.

\section{Results}

According to Chai, Zhang and Tan (2005), the initial step for the application of the methodology is the identification of a service problem. Phase 1 constitutes the definition of the problem, which is then "translated" into the language of TRIZ. In phase 2, the problem is structured as the typical contradictions of TRIZ, through the analysis of contradictions, one of the most effective tools in solving problems. For the elimination of inconsistencies, it uses the inventive principles basement 40 . Finally, in phase 3 , the ideas of solution are evaluated as the sole criterion of TRIZ, ideal final result. That this is a list of possible innovative solutions for design services. If someone do not find the optimal solution and other new problems arise restart the process.

\section{Stage 1: Problem Definition}

- Situation analysis

Uses the definition of the problem to obtain valuable information about the real situation that will lead to preliminary analysis of the context (CHAI; ZHANG; TAN, 2005). From the questionnaires, we identified the elements limiting the terminal divided into three activities: receipt, storage and delivery of cargo.

\section{- Problem modeling and formulation}

When the situation analysis is completed, the next step is the construction of a function diagram, using the function analysis, as presented in Figure 4. By using the formulator problem, a set of events are extracted and related to each other using cause-effect. Based on the functional diagram, problem statements are formulated. This model was inspired by the work of Chai, Zhang and Tan (2005).

\section{Stage 2: Problem Resolution}

\section{- Contradiction analysis}

The analysis of contradictions, the situation can be interpreted as a layout problem, which is shown as one of the main problems behind everyone else. In the case discussed, 


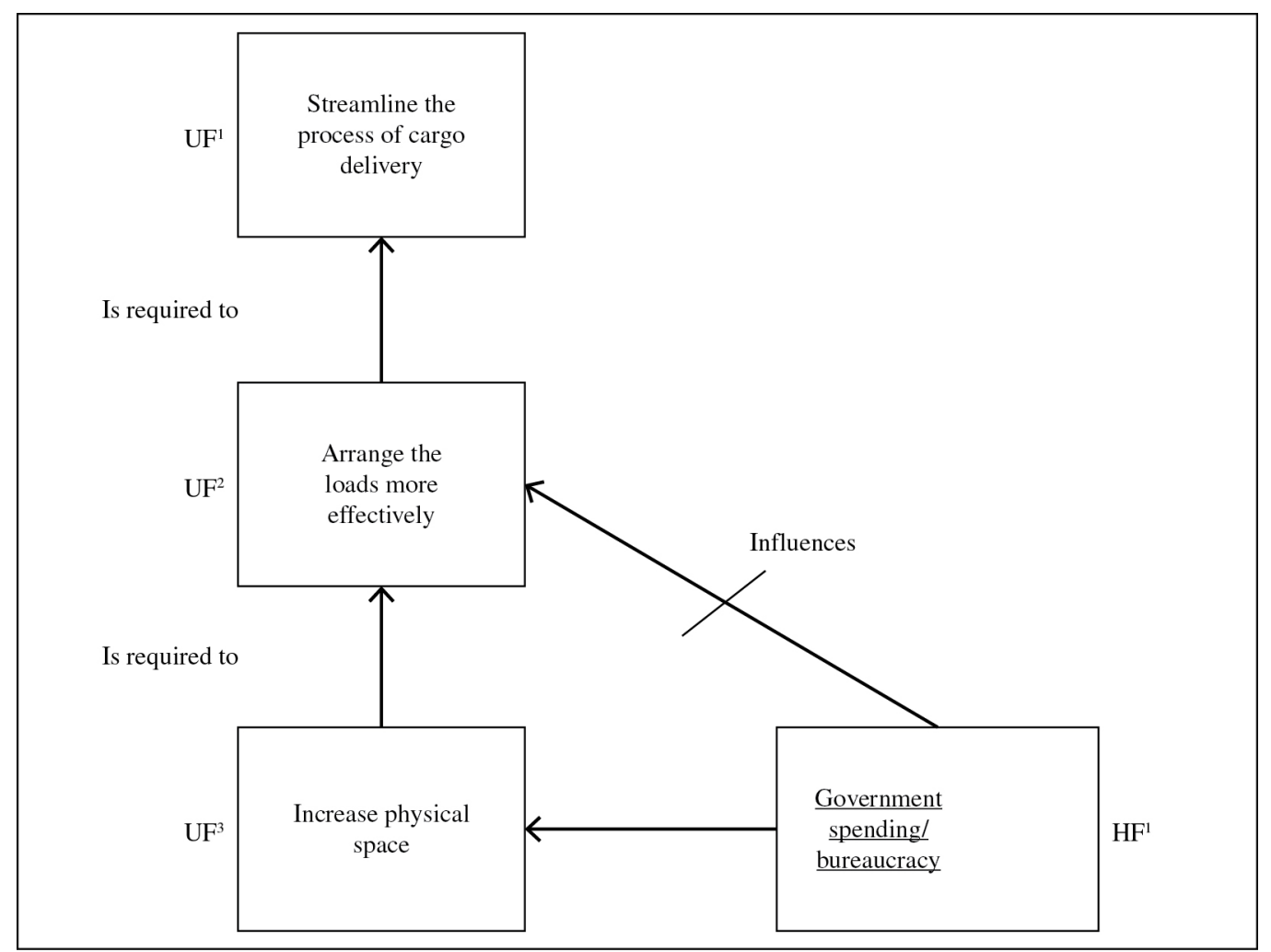

Figure 4. Model for problem resolution. Source: Survey data (2012), adapted from Chai, Zhang and Tan (2005). UF = Useful Function; $\mathrm{HF}=$ Harmful Function; $\mathrm{UF}^{1}=$ Expedite the process of cargo delivery to meet demand; $\mathrm{UF}^{2}=$ Arrange loads more effectively; $\mathrm{UF}^{3}=$ Increase physical space; $\mathrm{HF}^{1}=$ Public expenditures / bureaucratic.

the two conflicting aspects in the original system are: the limited physical space and high demand from customers. The contradiction can be structured such that the space should be large enough to meet the needs of cargo storage. However, spending and bureaucracy make impracticable required for this increased space as shown in Figure 5.

\section{Stage 3: Solution Evaluation}

The main activities of this phase are presented in Figure 6.

\section{- Formulate ideal solution}

The ideal solution to solve this problem should incur the lowest possible cost while providing maximum benefit to the system operations.

\section{- Prioritize ideas}

Among the insights obtained in steps of the resolution phase of problems, the most appropriate would be to change the layout, and the introduction of the storage technique by popularity, in that products are spread over the depot according to their popularity, or those that have a greater flow would be close to the outputs of the storage unit.

\section{- Formulate local constraints}

The cargo terminal has studied as the main constraint limited physical space; however, it was noted that the problem is more on optimizing the available space than necessarily the implementation of new storage spaces.

\section{- Refine ideas}

The optimization of the layout shows up as a viable solution that does not require financial outlays.

\section{Conclusion and managerial implications}

This study proposes a new way of solving logistical problems based on TRIZ methodology. TRIZ is distinguished from other methods of resolving problems due to its ability to generate innovative ideas (CHAI; ZHANG; TAN, 2005). Because of the early applications of TRIZ have been in the engineering field, many of its principles and tools were originally developed for solving technical problems. However, there are efforts to expand the possible applications of TRIZ also for managerial areas. The several tools can be equally effective in solving technical problems and non-technical, as presented by Mann and Domb (1999), who adapted the 40 inventive principles of TRIZ to business management.

Although the literature of practical cases of application of TRIZ is scarce, the search results proved satisfactory. It was possible to identify bottlenecks in the logistics system 


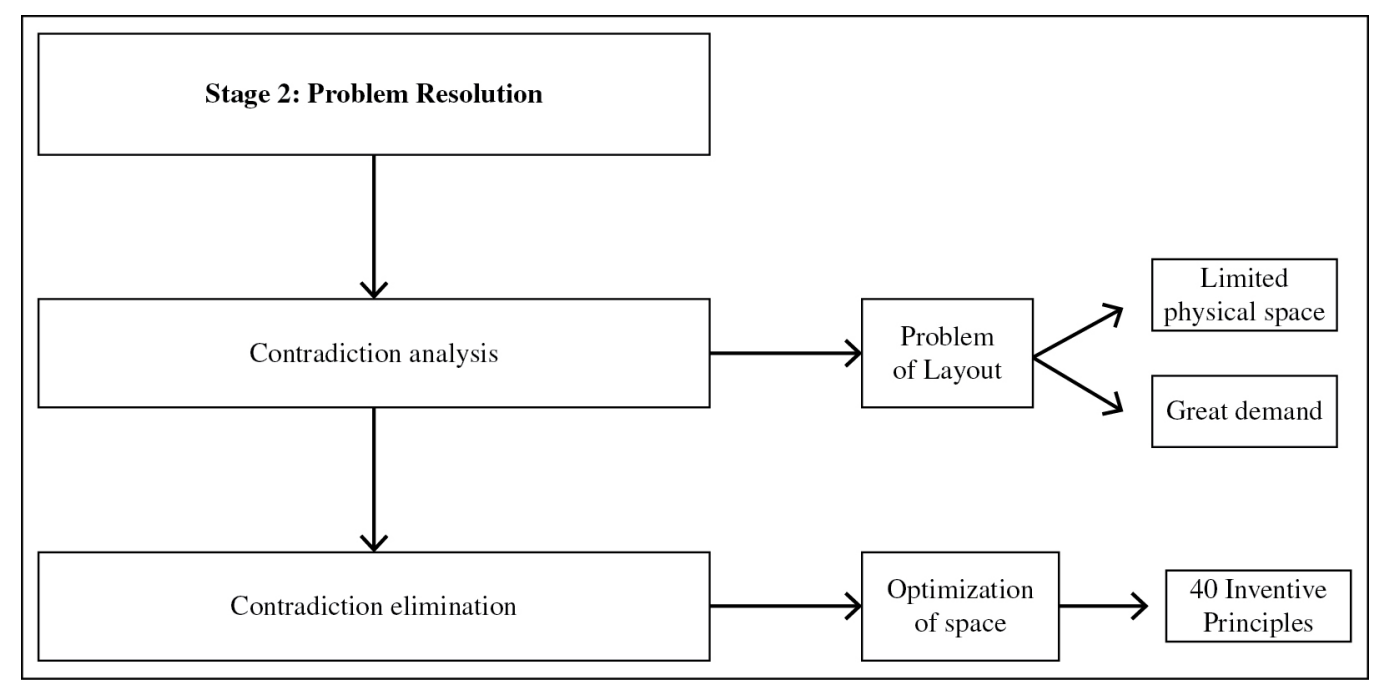

Figure 5. Problem resolution. Source: Survey data (2012), adapted from Chai, Zhang and Tan (2005).

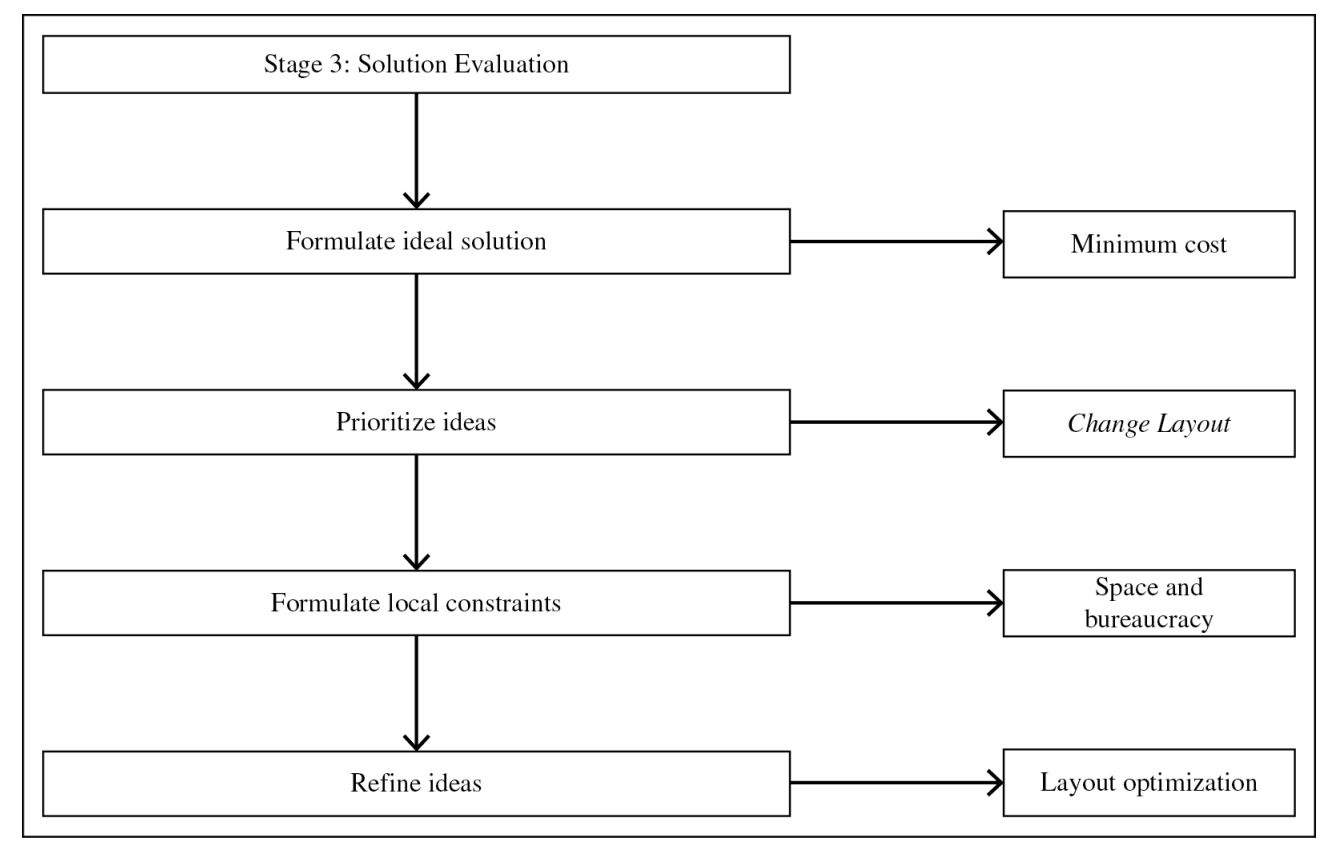

Figure 6. Solution evaluation. Source: Survey data (2012), adapted from Chai, Zhang and Tan (2005).

of the airport terminal loads studied, indicating the source of the problem for the disposition of the cargo tank. The change in strategy of storage demonstrated a way to optimize the physical space currently available in the terminal, which results in increased operational quality.

One limitation of this study is the analysis of only one case. To overcome this limitation, future research, the use of multi case studies, can validate the feasibility of applying TRIZ to solve several kinds of logistical problems.

The results obtained in this study can contribute to the logistics management as a whole. However, the activities of transport, one of the key elements of this study, and storage will be most benefited, as were foci of analysis. In the context of air transport, the present work contributes to reduce the shortage of study with a focus on the ground services of air cargo terminals.

The new logistics perception shows that there is no longer an isolated analysis of the areas production, transport and distribution. What counts today is the integration by promoting speed and quality processes, reducing costs and time, and the enjoyment of the new technologies available. In this sense, the findings of this research can be shared by companies of several branches of activity. The optimization of a storage space is favorable for any organization. The dissatisfaction among employees with some business processes, as happened in this case, is also a recurring within 
the organization. And yet, the increase of air transport, as already said, contribute socially and economically to global trade relationships, so the study has a notoriously practical and theoretical value.

\section{Acknowledgements}

National Council for Scientific and Technological Development (CNPq), The State of Goias Research Foundation (FAPEG) and the time of Professionals from Cargo Logistics Terminal (TECA) / Infraero, Goiânia-GO.

\section{References}

AIRPORT COUNCIL INTERNATIONAL - ACI. The social and economic impact of airports in Europe. York Aviation, 2004. Available from: <http://www.ryanair.com/ doc/news/2012/ACI-Report.pdf>.

BALLOU, R. H. Business Logistics - Importance and some research opportunities. Gestão \& Produção, v. 4, n. 2, p. 117-129, 1997.

BELSKI, I. et al. SARS and 40 Principles For Eliminating Technical Contradictions: Creative Singapore. TRIZ Journal, June 2003. Available from: <http://www.trizjournal.com/archives/2003/06/g/07.pdf>.

BOEING. World Air Cargo Forecast 2010-2011 Foreword. Available from: <http://www.boeing.com/assets/pdf/ commercial/cargo/wacf.pdf>. Access in: Dec 2011.

BOWERSOX, D. J.; CLOSS, D. J. Brazilian Logistics: A time for transition. Gestão \& Produção, v. 4, n. 2, p. 130-139, 1997. http://dx.doi.org/10.1590/S0104530X1997000200002

CHAI, K.-H.; ZHANG, J.; TAN, K.-C. A TRIZ - Based Method for New Service Design. Journal of Service Research, v. 8, n. 1, p. 48-66, Aug 2005. http://dx.doi. org/10.1177/1094670505276683

COUNCIL OF SUPPLY CHAIN MANAGEMENT PROFESSIONALS - CSCMP. Supply Chain Management Terms and Glossary. CSCMP, Aug 2013. Available from: <http://cscmp.org/sites/default/files/user_uploads/ resources/downloads/glossary-2013.pdf>.

HAN, T. C.; CHOU, T. Y.; LIANG, G. S. A demand analyses of cargo terminal in Taiwan's International. Journal of the Eastern Asia Society for Transportation Studies, v. 5, p. 12-34, Oct 2003.

HSU, C.-I.; SHIH, H.-H.; WANG, W.-C. Applying RFID to reduce delay in import cargo customs clearance process. Computers \& Industrial Engineering, v. 57, p. 506-519, 2009. http://dx.doi.org/10.1016/j.cie.2008.02.003
LI, T. Applying TRIZ and AHP to develop innovative design for automated assembly systems. International Journal of Advanced Manufacturing Technology, v. 46, p. 301-313, 2010. http://dx.doi.org/10.1007/s00170-0092061-4

LLEVBARE, I. M.; PROBERT, D.; PHAAL, R. A review of TRIZ, and its benefits and challenges in practice. Technovation, v. 33, n. 2-3, p. 30-37, 2013. http://dx.doi. org/10.1016/j.technovation.2012.11.003

LÓPEZ, J.; ALMEIDA, R. L.; ARAUJO-MOREIRA, F. M. TRIZ: Criatividade como uma ciência exata? Revista Brasileira de Ensino de Física, v. 27, n. 2, p. 205-209, 2005. http://dx.doi.org/10.1590/S1806-11172005000200004

MANN, D.; DOMB, E. 40 inventive (business) principles with examples. TRIZ Journal, 1999. Available from: <http:// www.triz-journal.com/archives/1999/09/a/>.

OHASHI, H. et al. Choiceofair cargo transshipment airport: an application to air cargo traffic to/from Northeast Asia. Journal of Air Transport Management, v. 11, p. 149-159, 2005. http://dx.doi.org/10.1016/j. jairtraman.2004.08.004

SAVRANSKY, S. D. Engineering of Creativity: Introduction to TRIZ Methodology of Inventive Problem Solving. Boca Raton: CRC Press, 2000. http://dx.doi. org/10.1201/9781420038958

UNITED NATIONS CONFERENCE ON TRADE AND DEVELOPMENT - UNCTAD. Development of Multimodal Transport and Logistics Services. Geneva: United Nations, 2003. TD/B/COM.3/EM.20/2.

VAN OUDHEUSDEN, D. L.; BOEY, P. Design of an automated warehouse for air cargo: The case of the Thai Airways Cargo Terminal. Journal of Business Logistics, v. 15, p. 261-285, 1994.

WORLD BANK. Air Freight: A Market Study with Implications for Landlocked Countries. Aug 2009. Available from: <http://trid.trb.org/view.aspx?id=917634>.

ZHANG, J.; CHAI, K.; TAN, K. 40 Inventive Principles with Applications in Service Operations Management. The TRIZ Journal, Dec., 2003. Available from: <http://www. bmgi.com/research/40-inventive-principles-applicationsservice-operations-management $>$.

WAN, Y.-W. et al. Warehouse location problems for air freight forwarders: a challenge created by the airport relocation. Journal of Air Transport Management, v. 4, p. 201-207, 1998. http://dx.doi.org/10.1016/S09696997(98)00024-6 